\title{
Evaluation of surgical outcome in open globe injuries in a tertiary ophthalmological centre
}

\author{
Dahal P, ${ }^{1}$ Byenju RN ${ }^{2}$ \\ ${ }^{1}$ Lecturer, Department of Ophthalmology, College of Medical Sciences \& Teaching Hospital, \\ Bharatpur,Chitwan, Nepal \\ ${ }^{2}$ Professor, Bharatpur Eye Hospital
}

\section{ABSTRACT}

\section{Aims}

To evaluate the clinical presentations and surgical outcome in patients with open globe injuries in a tertiary ophthalmological centre in Bharatpur Eye Hospital, Bharatpur.

\section{Methods}

Seventy nine patients with ocular injury who underwent surgery were included in the study. The type of injury, surgical interventions and final visual outcome were recorded. The period of study was from 2012 May to 2013May.

\section{Results}

Injury was mild in 48 (60.8 \%), moderate in 17 (21.5\%) \& severe in 14 (17.7\%) cases (International Ocular Trauma Classification). Forty six (58.2\%) cases had only primary repair, 27 (34.2\%) had associated lens extraction, $12(15.2 \%)$ had vitrectomy, 2 (2.5\%) had retinal detachment surgery, one $(1.3 \%)$ had intra-ocular foreign body removal, one (1.3\%) evisceration. Thirteen $16.5 \%)$ cases underwent secondary procedures. Final vision was $6 \backslash 18$ or better in 20 (25.3\%), 6\18-6\60 in 14 (17.7\%) and $<6 \backslash 60$ in 15 (18.9\%) cases. 10 (12.7\%) cases developed phthisical changes.

\section{Conclusion}

Present analysis reveals that open globe injuries can present in varying severity \&though the overall prognosis is grave, prompt surgical intervention can result in better visual outcome.

Key words: open globe injury, surgical outcome, visual outcome, grave prognosis

\section{INTRODUCTION}

Ocular trauma which was once neglected has now gained attention as a major cause of visual morbidity. Around the world half a million blinding injuries occur every year, there are approximately

Correspondence to: Dr. Polina Dahal

Email:polinadahal@yahoo.com
1.6 million people blind from eye injuries, 2.3 million bilaterally visually impaired and 19 million with unilateral visual loss; this being the commonest cause of unilateral blindness today. ${ }^{1,2,3,4}$ Maximum incidence is found in young adults and elderly ${ }^{5,6}$ and is much more common in males ${ }^{7,8}$. As such, the cost of ocular trauma to the society is 
Journal of College of Medical Sciences-Nepal, 2013, Vol-9, No-2,

related not only to medical treatment, but also to a

lifelong loss of productivity. Approximately half of all the patients present to an eye casualty department because of ocular trauma. ${ }^{9,10}$ The globe injuries can be classified into open globe injuries and closed globe injuries. In an open globe injury there is a full thickness wound of the eye wall (corneo-sclera) whereas in a closed globe injury the eye wall does not have a full thickness wound. ${ }^{11}$ The spectrum of injuries ranges from mild, nonsight threatening to extremely serious with potentially blinding consequences. Only $2-3 \%$ of all eye injuries require hospital admission and it is this small minority of cases that are of interest and concern with regard to management and outcome, and therefore have attracted most attention. ${ }^{8,9}$ In the present study, we did a prospective study of 79 cases of open globe injury presenting to Bharatpur Eye Hospital, Bharatpur with regard to the clinical presentation, the time of presentation after injury and outcome of surgical management during 6 months follow up. Patients were identified, who had undergone open globe repair alone or with secondary repair. For grading the injuries, the anatomic and physiologic variables identified in the International Ocular Trauma Classification were used (Table 1). This classification system categorises open globe patients by:

1. Visual acuity at the time of presentation
2. Pupillary reaction in the affected eye.

3. The extent of laceration

4. The type of injury: penetrating, perforating and rupture with or without intra ocular foreign body. The results of this suggests that the determinants for an acceptable outcome in patients with open globe injuries depend upon the severity of injury, time of presentation and institution of prompt treatment.

\section{METHODS}

This is prospective study included 79 cases of open globe injury that underwent surgical repair during 2012May - 2013May at Bharatpur Eye Hospital, Bharatpur. Patients who had ocular injuries and needed surgery were randomly included in the study. Children in whom vision could not be recorded and patients with no light perception at the time of presentation were excluded from the study. Patient evaluation at presentation included detailed history of the injury, Snellen's visual acuity, slit lamp examination, intraocular pressure, fundus examination (if possible), and ultrasonography (wherever necessary). The severity was graded as mild, moderate or severe on the basis of the score given to each factor as shown in table 1 (American Association for the Surgery of Trauma. ${ }^{12}$ ) 
Dahal P et al. Evaluation of surgical outcome in open

Table 1: The ocular trauma severity score

\begin{tabular}{|c|c|c|c|c|}
\hline Score & Visual Acuity & Pupil & Zone & Type \\
\hline 0 & & Negative & & \\
\hline 1 & $>6 / 18$ & $\begin{array}{c}\text { Afferent Pupillary } \\
\text { Defect }\end{array}$ & $\begin{array}{l}\text { I-isolated to } \\
\text { cornea }\end{array}$ & Penetrating \\
\hline 2 & $6 / 18-6 / 60$ & & $\begin{array}{l}\text { II-5mm posterior } \\
\text { to Limbus }\end{array}$ & Perforating \\
\hline 3 & $<6 / 60$ & & $\begin{array}{l}\text { III-posterior to } \\
\text { anterior } 5 \mathrm{~mm} \\
\text { of the sclera }\end{array}$ & Rupture \\
\hline 4 & & & & IOFB \\
\hline $\begin{array}{l}\text { d:3-5, } \\
\text { derate:6-8, } \\
\text { ere: } 9-11\end{array}$ & & & & \\
\hline
\end{tabular}

The Surgical procedures were classified as Primary (performed following first presentation) and secondary (performed later following primary procedure). Surgeons at the institution had similar amounts of surgical experience and similar surgical approaches towards patients with open globe injuries. At our institution open globes or suspected open globes are emergently explored and repaired in the operating room. Corneal or scleral lacerations are primarily closed with non absorbable suture such as 8-0, 9-0 nylon. Uveal prolapse is either reposited into the eye or excised. Vitreous at the wound if present is carefully excised. If needed IOL implantation after lens extraction, vitrectomy, IOFB removal or RD surgery is done at the same sitting. Post operatively patient receives broad spectrum topical and systemic antibiotics. As per requirements, depending upon the course of postoperative recovery, other secondary surgeries are performed. Patients' ocular status at 6 months postop. was taken as the final status. The vision was graded as good (VA 6/12 or better), fair (VA between 6/18 and 6/60) and poor (VA less than 6/ $60)$. It is seen whether the time of presentation after the injury had influenced the final outcome.

\section{RESULTS}

Out of 79 cases of open globe injury, males were 69 and females were 10. Age of the patients varied between 04 to 70 years (mean 37 years). Followup was up to 6 months postoperatively. Out of the 79 cases, the nature of injury was penetrating in $71(89 \%)$ and $08(10.12 \%)$ were blunt injuries. Injury was mild in $48(60.8 \%)$ cases, moderate in $17(21.5 \%)$ and severe in $14(17.7 \%)$ cases. At presentation, one $(1.3 \%)$ patient had visual acuity $>6 / 18,5(6.3 \%)$ had visual acuity between $6 / 18$ to 6/60 and $73(92.4 \%)$ patients had visual acuity < 6/60 (Table 2). 
Journal of College of Medical Sciences-Nepal, 2013, Vol-9, No-2,

Table 2: presenting visual acuity

\begin{tabular}{cc|}
\hline Vision & No. of patients \\
$\geq 6 / 12$ & $01(1.3 \%)$ \\
$6 / 18-6 / 60$ & $05(6.3 \%)$ \\
$<6 / 60$ & $73(92.4 \%)$ \\
\hline
\end{tabular}

All underwent surgery following initial general management. Forty six (58.2\%) cases had only primary repair, $27(34.2 \%)$ had associated lens extraction, $11(13.9 \%)$ had intra-ocular lens implantation, 12 (15.2\%) had vitrectomy, 2 (2.5\%) had retinal detachment surgery, one $(1.3 \%)$ intraocular foreign body removal, one (1.3\%) evisceration.13 (16.5\%) cases underwent secondary procedures: lens extraction in $9(11.4 \%)$ cases, intra-ocular lens implantation in $3(3.8 \%)$ cases, retinal detachment surgery in 7 (8.9\%), vitrectomy in $4(5.06 \%)$, intra-ocular foreign body removal in $1(1.3 \%)$ and evisceration in $3(3.8 \%)$ cases (Table 3). Final visual outcome was good in $20(25.3 \%)$ cases, fair in $14(17.7 \%)$ cases and poor in 15 (18.9\%) cases (Table 4). 10 (12.7\%) cases developed pthisisical changes. 20 (25.3\%) cases were lost to follow up. Six out of 26 patients who received attention on the same day of injury regained vision up to 6/6. In 06 out of 46 patients receiving attention within a week regained vision up to 6/9 and one out of 07 patients receiving attention after 1 week had visual recovery up to $6 / 12$.
Table 3: Surgical procedure

\begin{tabular}{l|l|l}
$\begin{array}{l}\text { Surgical } \\
\text { procedure }\end{array}$ & $\begin{array}{l}\text { No. of } \\
\text { patients }\end{array}$ \\
Primary: & Repair & $46(58.2 \%)$ \\
& Repair+lens extraction & $27(34.2 \%)$ \\
& Repair+IOL & $11(13.9 \%)$ \\
Repair+vitrectomy & $12(15.2 \%)$ \\
Secondary: & Lens extraction & $01(1.3 \%)$ \\
& Repair+RD surgery & $02(2.5 \%)$ \\
& Evisceration & $01(1.3 \%)$ \\
& RD surgery & $09(11.4 \%)$ \\
& Vitrectomy & $03(3.8 \%)$ \\
IOFB removal & $04(8.9 \%)$ \\
Eviceration & $03(3.8 \%)$
\end{tabular}

Table 4: Final visual status

$\begin{array}{ll}\text { Vision } & \text { No. of Patients } \\ \geq 6 / 12 & 20(25.3 \%) \\ 6 / 18-6 / 60 & 14(17.7 \%) \\ <6 / 60 & 15(18.9 \%)\end{array}$

\section{DISCUSSION}

Open globe injuries can present with varying severities depending on the site of injury, nature of injury, associated damage, degree of hemorrhage, presence of intraocular foreign bodies and time of presentation. ${ }^{13,14}$ Detailed history as regards time, place, nature of injury; thorough examination of the eyes including vision, papillary reflexes, slit 
lamp examination, intraocular pressure, dilated fundus examination (if possible), B-scan ultrasonography (if media is hazy / foreign body is suspected), and immediate institution of antibiotic and / or antifungal eye drops, cycloplegics, osmotic agents, systemic antibiotics, analgesics, tetanus toxoid injection depending on the case is a must. Though open globe injuries are associated with a poor visual and anatomical outcome, this study suggests that the institution of prompt treatment has an important effect on the final outcome. An open eye should be repaired as soon as possible and repair of a rupture or penetrating wound should always be attempted, even in an apparently disrupted eye, as it is not possible to predict the prognosis at the time of presentation. Scleral lacerations or ruptures require primary closure as soon as possible to restore normal anatomical relationships and reform the collapsed eye 258 without incarceration of uveal tract or vitreous in the wound. ${ }^{15}$ Associated procedures which might be required are lens extraction with or without intraocular lens implantation, vitrectomy, intra-ocular foreign body removal, retinal detachment surgery. Secondary procedures including lens extraction, retinal detachment surgery, vitrectomy, intra-ocular foreign body removal might also be required later on. This study analyzed 79 cases of open globe injuries which presented at different intervals following injury with varying degrees of severity. Male patients out numbered females (69:10) and was more common in the active age group. All patients received attention immediately on presentation. Surgical intervention was required in all the cases. Visual recovery was noticeably better in patients who presented early, but it was also dictated by the severity of injury. At the end of 6 months, 20 (25.3 $\%)$ patients regained good vision,14 (17.7\%) patients regained fair vision and $15(18.9 \%)$ regained poor vision. $4(5.06 \%)$ cases had evisceration and $10(12.7 \%)$ cases developed pthisisical changes. A review of experience indicates a very significant impact of eye injuries in terms of medical care, needs for vocational rehabilitation and great socioeconomic costs. ${ }^{2}$ Though the prognosis of open globe injuries has improved with the development of advanced microsurgical techniques and better understanding of tissue reaction to trauma. ${ }^{13}$ However, the present study has some limitations. Firstly, the time interval up to the second surgical intervention and its course has not been studied owing to limited patient documentation or irregular numbers of follow-up. Secondly, the range of final visual acuity has not been seen who had presented on the same day, within a week or one week after the injury, so as to keep the study confined to one aim only.

\section{CONCLUSION}

This study suggests that the severity of injury, time of presentation and institution of prompt treatment are also very important determinants in the final visual and anatomical outcome. Therefore, given the large number of patients at risk of visual impairment due to ocular trauma warrants the use of protective eye wears during work, sports, travel etc. which carries chances of injury, because, prevention is the best cure. Also, it warrants early referral of such cases by the attending doctor to well equipped centres having trained and experienced ophthalmologists. 


\section{REFERENCES}

1. Parver L. Eye trauma. The neglected disorder.Arch Ophthalmol 1986; 104(10): 1452-3

2. Negrel AD, Thylefors B. The global impact of eye injuries. Ophthalmic Epidemiol 1998;5(3): 143-69

3. Kahn HA, Moorhead HB. Statistics on blindness in the model reporting area- 19691970, US Department of Health, Education and Welfare publication Bethesda: National Institute of Health, National Eye Institute;1973: 73-27.

4. National Society to prevent Blindness: Vision problems in the United States: Data Analysis.New York: National Society to Prevent Blindness; 1980.

5. Glynn RJ, Seddon JM, Berlin BM. The incidence of eye injuries in New England.Arch Ophthalmol 1988; 106(6): 785-9

6. Desai P, MacEwen CJ, Baines P, Minaissian DC. Epidemiology and implications of ocular trauma admitted to hospital in Scotland. $J$ Epidemiol Community Health 1996; 50(4):436-41

7. Schein OD, Hibberd PL, Shingleton BJ,Kunzweiler T, Frambach DA, Seddon JM, Fontan NL, Vinger PF. The spectrum and burden of ocular injury. Ophthalmology 1988; 95(3): $300-5$
8. MacEwen CJ.Eye injuries: a prospective survey of 5671 cases. Br J Ophthalmology 1989; 73(11): 888-94

9. Chiapella AP, Rosenthal AR. 1 year in an eye casualty clinic. $\mathrm{Br} J$ Ophthalmoogyl 1985;69(11): 865-70.

10. Vernon SA. Analysis of all new cases seen in a busy regional centre ophthalmic casualty department during 24- week period. $J R$ Soc Med 1983; 76(4): 279- 82

11. Pieramici DJ, Sternberg P, Aaberg TM,Bridges WZ, Capone A, Cardillo JA, etal. A system of classifying mechanical injuries of the eye (globe).Am J Ophthalmol 1997;123: 820- 31.

12. Ernest EM, Mark AM, Thomas HC. Organ injury scaling VII. J Trauma. 1996; 41:52325.

13. Caroline J. MacEwen.Ocular injuries. J.R.Coll. Surg. Edinb, 44, October 1999, 317-23.

14. Sternberg P Jr: Trauma: Principle and technique of treatment, in Ryan SJ(ed):Retina.St. Louis, CV Mosby Co., 1989, Vol 3,PP 469-495.

15. Ryan SJ, Liggett PE: Posterior penetrating ocular trauma, in Ryan SJ(ed):Retina.St.Louis, CV Mosby Co. 1989, vol 3,PP 455- 468. 